\title{
Pengembangan Pusat Pemantauan Central SpO2 untuk Ruang Neonate denga Sistem Wireless
}

\author{
Mirza Fissabila \#, Priyambada Cahya Nugraha, Muhammad Ridha Mak'ruf \\ Jurusan Teknologi Elektro-medis, Poltekkes Kemenkes Surabaya \\ Jl. Pucang Jajar Timur No. 10, Surabaya, 60282, Indonesia \\ \#fissabilamirza@gmail.com ,pcn1967@poltekkesdepkes-sby.ac.id,m.reedha@gmail.com
}

\section{Info Artikel \\ Penerimaan Artikel: \\ Diterima 9 Maret 2019 \\ Revisi 15 Des 2020 \\ Terbit 18 Des 2020}

\section{Kata kunci:}

Monitoring

$\mathrm{SpO} 2$

Max 30100

Fingertip Neonatal

HC-05

Arduino

\begin{abstract}
Abstrak
Monitoring status kesehatan bayi merupakan hal yang sangat penting khususnya pada bayi yang lahir secara prematur. Pemantauan kadar saturasi oksigen pada bayi baru lahir dapat membantu mendeteksi dini kelainankelainan bawaan pada bayi tersebut. Tujuan dari penelitian ini adalah untuk membuat dan mendisain sebuah alat yang dapat digunakan untuk melakukan pemantauan kondisi nilai Saturasi Oksigen ( $\mathrm{SpO2}$ ) beberapa pasien sekaligus secara kontinyu dengan jarak yg cukup jauh sehingga tenaga medis tidak perlu mendatangi satu persatu baby incubator secara berkala untuk melakukan pemantauan kadar nilai Saturasi Oksigen (SpO2) pasien di dalam baby incubator. Dimana pada pembahasan penelitian kali ini akan membuat 2 modul alat monitoring yang dapat digunakan untuk memantau 2 bayi prematur pada baby incubator secara bersamaan menggunakan 2 sensor berbeda, yaitu pada modul 1 akan menggunakan sensor Fingertip Neonatal dan pada modul 2 akan menggunakan sensor Max 30100. Alat ini akan menampilkan nilai dan sinyal saturasi oksigen (SpO2) pada sebuah PC secara bersamaan. Pemantauan pada alat ini dilakukan secara wireless menggunakan modul Bluetooth HC-05. Berdasarkan dari hasil pengujian dan pengukuran modul yang telah di buat, pada 5 pasien berbeda dengan menggunakan pembanding pulse oxymeter pada sensor Max 30100 didapatkan nilai selisih sebesar 1\% pada masingmasing hasil pasien, pada sensor fingertip neonatal juga didapatkan nilai selisih $1 \%$ pada masing-masing pasien. Pada pengujian jarak, alat ini mampu memantau kondisi 2 pasien secara bersamaan dengan jarak maksimal 3,5 meter. Hasil penelitian ini dapat diimplementasikan pada sistem pemantauan pada ruang NICU untuk membantu mengurangi beban kerja tenaga medis dan untuk meningkatkan efektifitas pelayanan Rumah Sakit.
\end{abstract}

\begin{abstract}
Monitoring the health status of babies is very important, especially for babies born prematurely. Monitoring oxygen saturation levels in newborns can help detect early congenital abnormalities in these babies. The purpose of this study is to create and design a tool that can be used to monitor the condition of Oxygen Saturation (SpO2) values of several patients at once continuously with a great distance so that medical staff do not need to go one by one baby incubators periodically to monitor levels Oxygen Saturation (SpO2) value of the patient in the baby incubator. Where in the discussion of this study will make 2 monitoring tool modules that can be used to monitor 2 premature babies in a baby incubator simultaneously using 2 different sensors, namely in module 1 will use the Neonatal Fingertip sensor and in module 2 will use the Max 30100 sensor. it displays the value and oxygen saturation signal (SpO2) on a PC simultaneously. Monitoring on this device is carried out wirelessly using the Bluetooth module HC-05. Based on the test results and module measurements that have been made, in 5 different patients using a pulse oxymeter comparator on the Max 30100 sensor a difference of $1 \%$ was obtained in each patient's result, in the neonatal fingertip sensor also obtained a difference of $1 \%$ in each - each patient. In distance testing, this tool is able to monitor the condition of 2 patients simultaneously with a maximum distance of 3.5 meters. The results of this study can be implemented in a monitoring system in the NICU room to help reduce the workload of medical personnel and to improve the effectiveness of hospital services.
\end{abstract}

This work is an open access article and licensed under a Creative Commons Attribution-ShareAlike 4.0 International License (CC BY-SA 4.0).

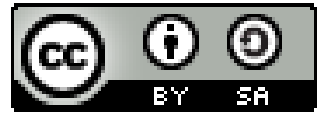

\section{PENDAHULUAN}

Saat ini pemantauan bayi prematur yang di letakkan pada baby incubator,masih di lakukan secara manual. Sistem pemantauan kesehatan penting dalam teknologi modern [1]Pada suatu instansi seperti sebuah rumah sakit, keberadaan alat monitoring sangat diperlukan untuk memantau kondisi pasien yang membutuhkan penanganan cepat sehingga setiap perubahan terhadap kondisi pasien harus selalu terpantau[2]. terutama pada pemantauan bayi prematur, Kelahiran prematur didefinisikan sebagai semua kelahiran sebelum 37 minggu kehamilan lengkap[3]. Sebanyak sebelas juta bayi prematur 
dilahirkan setiap tahun di seluruh dunia[4]Menurut penelitian lain, sebanyak 20 juta bayi lahir prematur, dan diperkirakan 450 diantaranya meninggal setiap jam[5].Kelahiran prematur merupakan salah satu faktor risiko utama kematian bayi baru lahir.[6]. Bayi prematur mengalami kondisi kesehatan yang lebih rumit dan menyebabkan kematian[7]. Berbeda dengan bayi cukup bulan, bayi prematur merupakan kelompok bayi yang berisiko tinggi. Hal tersebut disebabkan oleh ketidakmatangan sistem organ tubuh pada bayi prematur, seperti organ paruparu, jantung, ginjal, hati, dan sistem pencernaan[8]. Baby incubator memainkan peran penting dalam menyelamatkan hidup bayi prematur [9]. Pemantauan berkelanjutan terhadap parameter kesehatan juga sangat penting untuk bayi prematur yang dirawat di unit perawatan intensif neonatal (NICU) di rumah sakit[10]. Di unit perawatan intensif neonatal (NICU), denyut jantung, laju pernapasan, dan saturasi oksigen adalah tanda-tanda vital (VS) yang terus dipantau pada bayi [11], Dikarenakan pentingnya pasokan oksigen dalam tubuh manusia. Salah satu indikator yang sangat penting dalam supply oksigen didalam tubuh adalah Oksigen saturasi (SpO2). Karena oksigen saturasi bisa menunjukkan apakah hemoglobin dapat mengikat oksigen atau tidak. Sehingga kekurangan oksigen yang beresiko pada kerusakan organ-organ penting didalam tubuh dan kematian dapat ditanggulangi [12]. Persentase saturasi oksigen normal pada manusia sama pada seluruh jenjang umur, yakni 95\%$100 \%$ baik bagi bayi baru lahir maupun lansia [13]. Kadar saturasi oksigen pada bayi baru lahir sangat penting untuk diketahui karena ketika kadar saturasi oksigen pada bayi baru lahir rendah maka patut diwaspadai apakah terdapat kelainan hemodinamika pada bayi tersebut. Pengukuran kadar saturasi oksigen pada bayi baru lahir dapat membantu mendeteksi dini kelainan-kelainan bawaan pada bayi[14]. Oleh karena itu, Kadar SpO2 harus terus menerus di monitor/ di pantau[15]. Saat ini, para tenaga medis di dalam ruang neonatus harus mendatangi satu persatu bayi yang berada di dalam baby incubator secara berkala untuk memonitor kondisi vital bayi di dalamnya. Oleh karena itu, untuk mengurangi beban kerja para tenaga medis, dan mengurangi kemungkinan kesalahan pembacaan data pada pasien diperlukan alat yang dapat memantau kondisi vital khususnya parameter vital $\mathrm{SpO} 2$ beberapa bayi sekaligus dengan jarak yang cukup jauh, sehingga tenaga medis dapat memantau secara kontinyu kondisi vital bayi pada satu tempat.

Pada tahun 2015 Mr. Mamun melakukan penelitian dengan judul $A$ Wireless Based Temperature, Humidity and Light Intensity Monitoring System for Child Incubator [16] dalam penelitian tersebut belum terdapat monitoring yang digunakan untuk SpO2 bayi. Pada tahun 2015 Pallerla akhsay kumay dkk melakukan penelitian dengan judul Real Time Monitoring And Control Of Neonatal Incubator Using Lab View [17]dalam penelitian ini tidak memonitor kondisi vital bayi di dalam baby incubator. Pada tahun 2016 M.Priya dkk melakukan penelitian dengan judul Wireless Patient Health Monitoring System using LabVIEW [18] dalam penelitian tersebut menggunakan zigbee untuk penggunaan wireless.
Pada tahun 2017 Sujithanand A dkk melakukan penelitian dengan judul Infant Incubator Monitoring System With Remote Access (IIMRA)[19] belum terdapat parameter vital SpO2. Pada tahun 2019 Rajalakshmi.A dkk melakukan penelitian dengan judul A Survey on Neonatal Incubator Monitoring System [20] pada penelitian ini hanya fokus pada pemantauan alat baby incubator serta pernafasan bayi yang ada dilamnya saja.

Berdasarkan identifikasi masalah tersebut penulis ingin merancang alat pemantauan vital $\mathrm{SpO} 2$ pada bayi baru lahir via wireless, agar dapat memantau $\mathrm{SpO} 2$ bayi di dalam baby incubator secara terus menerus dan dapat dilakukan jarak jauh menggunakan PC dengan cara sentral monitor. Sehingga dapat meningkatkan efektifitas kerja para tenaga medis dalam melakukan pemantauan.

Artikel ini terdiri dari 5 Bagian, Bagian II berisi metode dan pengembangan yang akan dilakukan, Bagian III, merupakan hasil-hasil yang didapatkan pada penelitian ini, Bagian IV adalah pembahasan temuan-temuan, dan Bagian V adalah kesimpulan.

\section{BAHAN DAN METODE}

\section{A. Rancangan Penelitian}

Pada penelitian ini, dibuat 2 modul yang dapat memonitor saturasi oksigen 2 pasien secara bersamaan dalam 1 PC dengan jarak cukup jauh. Pengambilan data secara acak pada 5 responden.

\section{1) Alat dan Bahan}

Penelitian ini menggunakan 2 sensor $\mathrm{SpO} 2$ yang berbeda, yaitu sensor Max 30100 (Maxim, Texas) dan sensor Fingertip Neonatal (Oximax,China). Kedua hasil sadapan sensor akan diolah oleh Arduino dan akan dikirimkan dengan menggunakan HC-05 (Feasycom, China)lalu ditampilkan bersamaan pada sebuah PC.

\section{2) Percobaan}

Dalam penelitian ini setelah modul jadi, dilakukan pengujian menggunakan pulse oxymetry (contect,China) untuk membandingkan nilai hasil $\mathrm{SpO} 2$.

\section{B. Diagram Blok}

Gambar 1 merupakan diagram blok sistem, ketika alat dihidupkan, maka rangkaian power supply akan memasok tegangan pada keseluruhan modul, Sensor SpO2 akan digunakan sebagai mengambil data input berupa nilai dan sinyal saturasi oksigen. Saat sensor terpasang, akan mendeteksi kadar oksigen dalam darah (SpO2) dan untuk mendapatkan nilai sadapan pada sensor maka hasil akan diolah pada rangkaian PSA.

Output dari rangkaian PSA ini akan masuk dan diproses oleh mikrokontroler. Pada mikrokontroler terjadi pengolahan data yang masuk dari output rangkaian PSA, seperti menentukan referensi secara otomatis ketika modul dihidupkan. Mikrokontroler juga akan mengirim data yang telah diolah secara wireless ke PC. PC akan menampilkan data nilai dan sinyal presentase $\mathrm{SpO}$. 


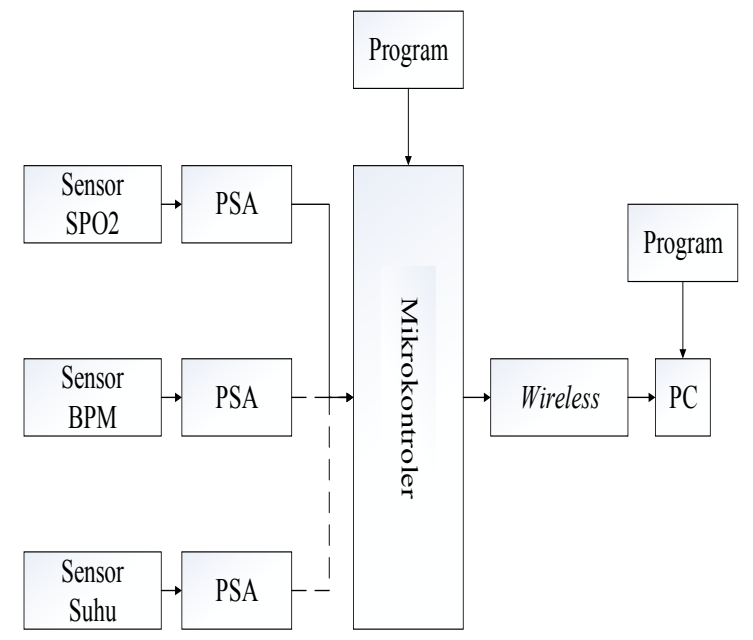

Gambar 1. Diagram Blok Sistem Pengolahan SpO2

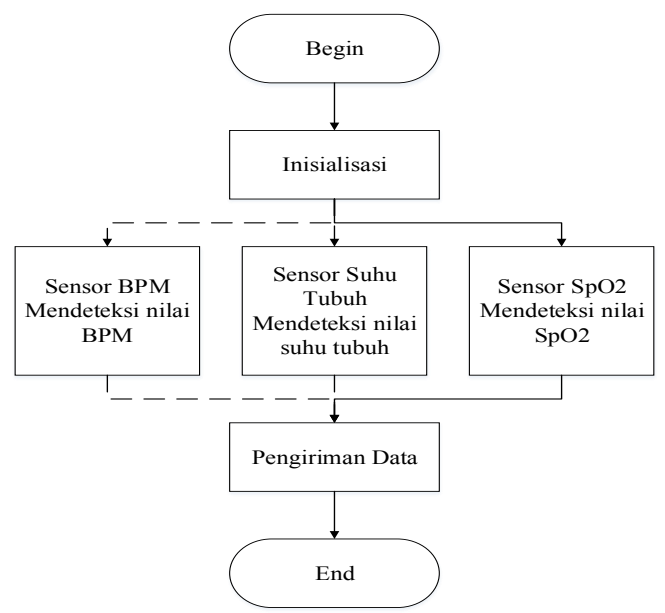

Gambar 2. Diagram Alir Program Pengolahan SpO2

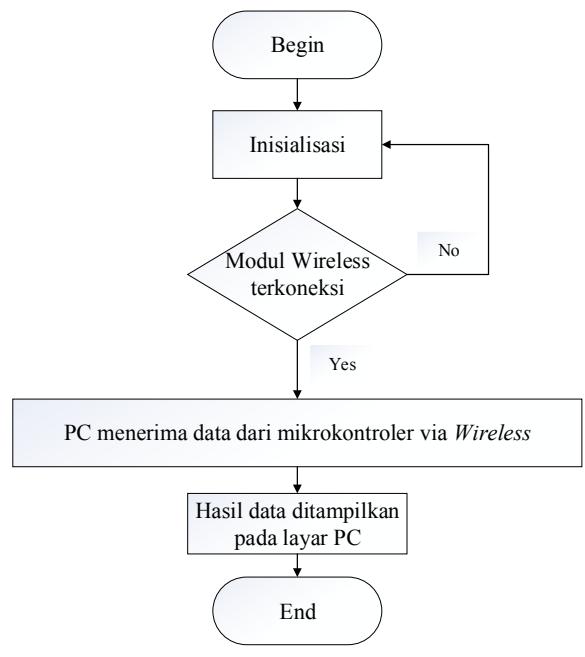

Gambar 3. Diagram Alir Penampil Pada PC

\section{Diagram Alir}

Pada diagram alir Gambar 2 ketika alat dihidupkan sensor $\mathrm{SpO} 2$ akan mendeteksi kadar saturasi oksigen dalam darah pasien, kemudian hasil yang telah didapatkan akan diproses oleh rangkaian ADC mikrokontroler setelah itu akan dikirim ke port serial menggunakan modul wireless. Kemudian dari modul wireless data akan dikirim dan diolah di PC untuk menampilkan nilai dan sinyal saturasi oksigen dalam darah.

Diagram alir Gambar 3 diawali dengan koneksi terhadap modul wireless apabila modul yang terpasang pada baby incubator sudah terkoneksi pada PC maka modul wireless pada PC yang akan berfungsi sebagai receiver dari baby incubator. Data yang diterima oleh modul wireless yang terdapat di PC nantinya akan diproses dan akan menampilkan nilai dan sinyal $\mathrm{SpO} 2$.

\section{Rangkaian Analog}

1)Rangkaian Analog Sensor Fingertip Neonatal

Sensor Fingertip Neonatal membutuhkan rangkaian untuk dapat menghasilkan nilai $\mathrm{SpO} 2$ berikut ini skematik rangkaian yang digunakan :

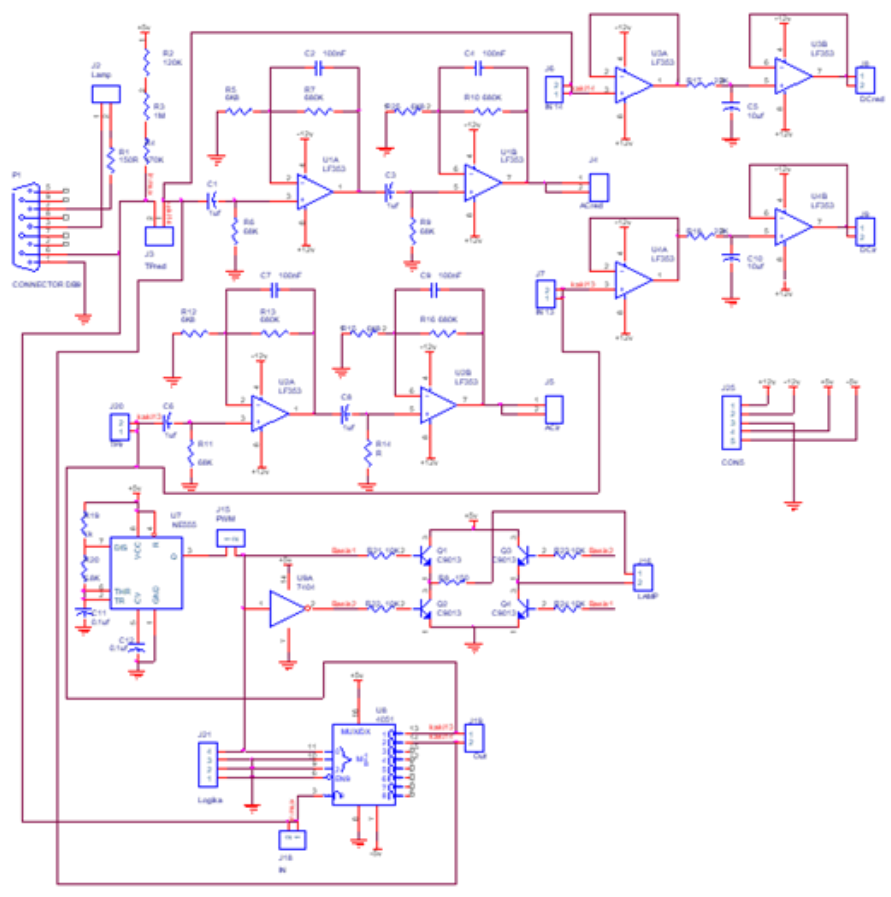

Gambar 4. Rangkaian Sensor Fingertip Neonatal

Gambar 4 merupakan rangkaian yang digunakan oleh Sensor SpO2 ( fingertip neonatal) yang akan mulai bekerja ketika alat sudah dalam posisi $O N$. Sensor akan mulai mendeteksi kadar saturasi oksigen pasien melalui aliran darah yang melewati photodiode.

Pada kondisi ini, terdapat rangkaian astable $1 \mathrm{KHz}$ yang berfungsi mengatur nyala dan mati pada red lamp dan 
infrared, rangkaian akan aktif secara bergantian dengan memberikan logika 1 dan logika 0 .

Output pada rangkaian astable di hubungkan dengan rangkaian transistor yang berfungsi sebagai driver pada sensor fingertip neonatal. Sehingga sensor akan bekerja mendeteksi aliran darah yang melewati sensor sesuai dengan logika yang diberikan.

Kemudian, output yang dihasilkan akan dihubungkan dengan rangkaian demultiplexer yang akan memisahkan output sadapan finger sensor menjadi sinyal infrared dan sinyal red lamp. Rangkaian ini berfungsi sebagai switching agar tidak adanya output yang keluar secara bersamaan.

Output demultiplexer akan dijadikan input pada 2 filter, yaitu filter LPF $0,8 \mathrm{~Hz}$ untuk mendapatkan sinyal DC dari infrared (DC IR) dan red lamp (DC RED). Serta output demultiplexer juga menjadi input pada rangkaian filter BPF untuk menghasilkan sinyal AC infrared (AC IR) dan red lamp (AC RED).

Filter BPF ini terdiri dari filter HPF pasif 2,34 Hz dan LPF aktif $2,34 \mathrm{~Hz}$. Filter HPF memiliki fungsi untuk meloloskan frekuensi di atas frekuensi cut-off dan filter LPF berfungsi untuk meloloskan frekuensi di bawah frekuensi cut-off serta menguatkan output.

Output sinyal AC IR, AC RED, DC IR dan juga DC RED dihubungkan dengan pin analog pada arduino dimana pin A1 adalah AC RED, pin A2 adalah AC IR, pin A3 adalah DC RED, dan pin A6 adalah DC IR. Kemudian data akan dikirim oleh Bluetooth $\mathrm{HC}-05$ ke PC berupa nilai dan sinyal saturasi oksigen.

\section{2)Modul Sensor Max 30100}

Gmbar 5 merupakan rangkaian pada sensor SpO2 (Max 30100) yang bekerja ketika alat sudah pada posisi $O N$ dan sensor sudah di letakkan pada posisi yang tepat, maka sensor akan langsung melakukan pembacaan kadar saturasi oksigen, dari aliran darah yang melewati sensor.

Data yang di ambil dari pasien langsung dikirim dan di proses pada arduino, setelah itu arduino akan melakukan pengiriman data pada PC melalui Bluetooth HC-05 untuk menampilkan nilai dan sinyal saturasi oksigen.

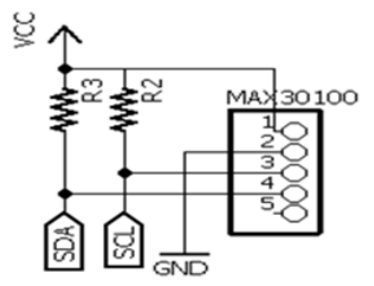

Gambar 5. Sambungan Sensor Max 30100 Sumber : http://teknokes.poltekkesdepkessby.ac.id/index.php/Teknokes/article/view/6

3)Modul Bluetooth
Gambar 6. merupakan sambungan Bluetooth. Modul Bluetooth akan terkoneksi dengan Arduinomenggunakan cara yaitu menghubungkan pin TX Arduino ke pin Bluetooth RX dan sebaliknya, pin RX Arduino ke pin Bluetooth TX.

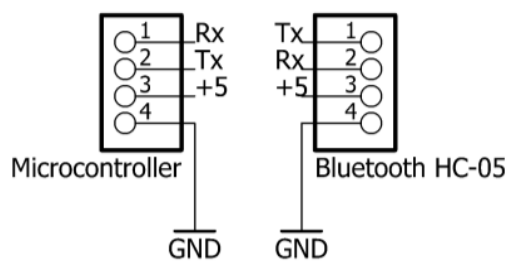

Gambar 6. Sambungan Bluetooth

Sumber : http://teknokes.poltekkesdepkessby.ac.id/index.php/Teknokes/article/view/6

\section{HASIL}

Dalam penelitian ini, telah dilakukan pengukuran pada 5 responden secara acak, dalam pengukuran ini didapat hasil presentase $\mathrm{SpO} 2$ normal pada tiap responden yaitu 97\%$100 \%$.

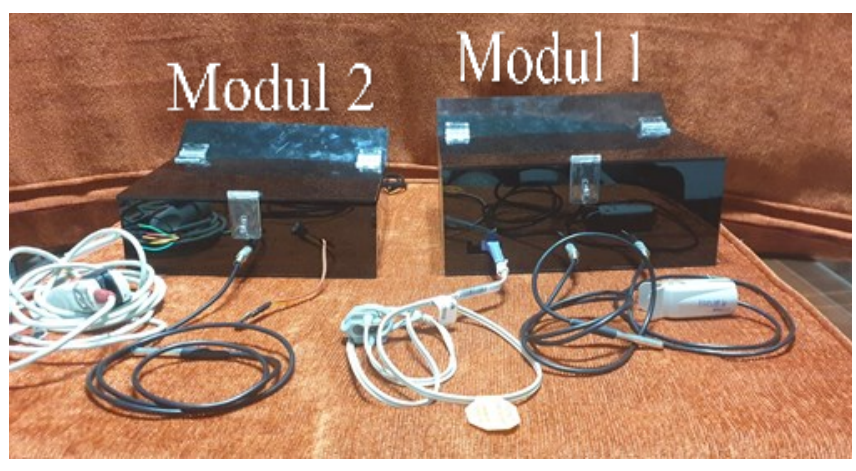

Gambar 7. Bentuk Modul yang telah dibuat

\section{1) Desain Modul}

Pada gambar 7 diatas merupakan bentuk fisik modul alat yang telah di buat, pada gambar terlihat masing- masing modul sedang terpasang 3 sensor yaitu sensor $\mathrm{SpO} 2$, sensor suhu dan sensor BPM (suhu dan BPM tidak dibahas penulis). Pada modul 2, merupakan modul dengan sensor SpO2 Max 30100, dan pada modul 1 merupakan modul dengan sensor $\mathrm{SpO} 2$ Fingertip Neonatal.

\section{2) Listing Program untuk Arduino}

Listing program 1 arduino merupakan program yang di gunakan pada modul 1 dengan sensor fingertip neonatal, di dalamnya terdapat program pengolahan data ADC, perhitungan nilai $\mathrm{SpO} 2$, tampilan sinyal $\mathrm{SpO} 2$, serta program pengiriman data pada PC.

Listing program 2 arduino merupakan program yang digunakan pada modul 2 dengan sensor Max 30100 yang berisi pengolahan nilai dan sinyal $\mathrm{SpO} 2$ serta pengiriman data yang telah di sadap pada PC.

Listing program 1.SpO2 sensor Fingertip Neonatal 
\#include $<$ Wire.h $>$

\#include $<$ SoftwareSerial.h $>$

const long interval $=5000$;

unsigned long previousMillis $=0$;

unsigned char tampilkan $=0$;

unsigned char spo $2=0$;

unsigned int maksimumACredlamp $=0$, maksimumACinfrared $=0 ;$

unsigned char counteran $=0$;

int logika, holdACinfrared;

float ratio $=0$;

float bagi1, bagi2;

int nodetak $=0$;

unsigned char cekdetak $=0$;

void $\operatorname{setup}()$

\{

Serial.begin(9600);

Serial.println("mulai");

Serial.println("CLEARDATA");

Serial.println("LABEL,Waktu,Refresh,Data");

Serial.println("RESETTIMER");

\}

void $\operatorname{loop}()$

\{

\{

//SPO2

if (millis() - tsLastReport > waktuSPO)

\{

float ACredlamp = analogRead(A1);

float ACredlamp $1=($ ACredlamp $/ 1023) * 5$;

float ACinfrared $=\operatorname{analog} \operatorname{Read}(\mathrm{A} 2)$;

float ACinfrared $1=($ ACinfrared $/ 1023) * 5$;

float DCredlamp = analogRead(A3);

float DCredlamp $1=($ DCredlamp $/ 1023) * 5$;

float DCinfrared $=\operatorname{analog} \operatorname{Read}(\mathrm{A} 5)$;

float DCinfrared $1=($ DCinfrared $/ 1023) * 5$;

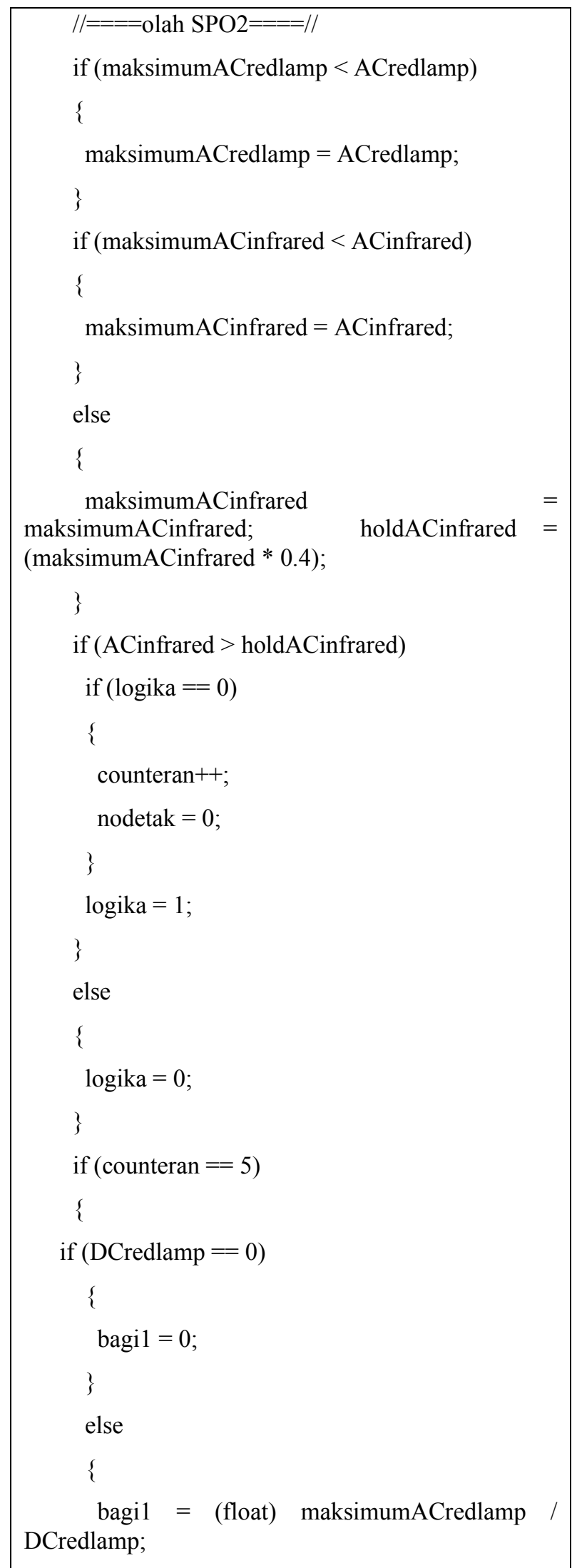




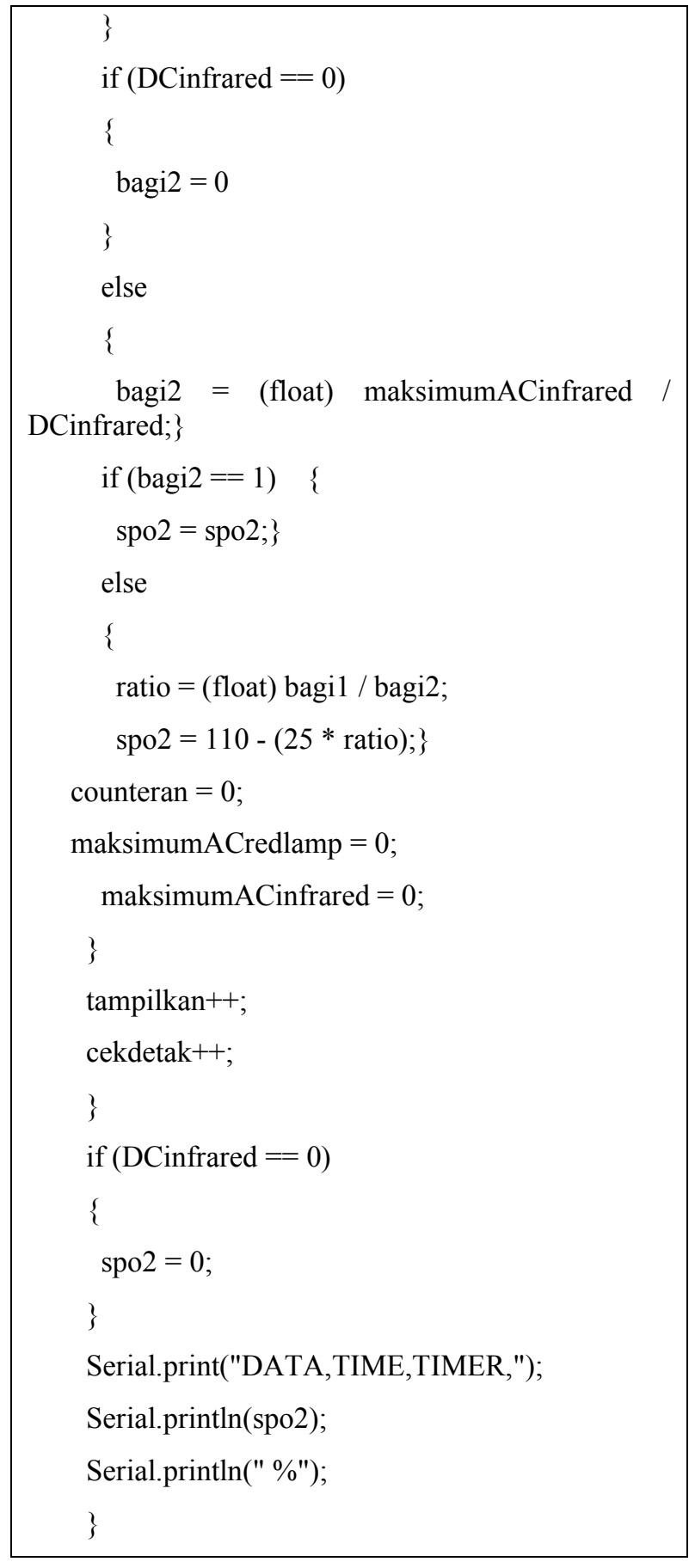

Listing Program 2. Program inisialisasi sensor Max 30100

// Inisialisasi Library MAX30100
\#include < LiquidCrystal.h>
// Inisialisasi Library LCD 16x2
//Inisialisasi variable SPO
\#define REPORTING_PERIOD_MS 1000

//Inisialisasi waktu yang digunakan MAX30100

PulseOximeter pox;

//Inisialisasi mengupdate pembacaan MAX30100

uint32_t tsLastReport $=0$;

$/ /=============$ TIMER $===========$

unsigned long milidetik1;

unsigned long milidetik2;

int milidetik3;

//Inisialisasi tipe data timer milidetik 1,2 dan 3

float average,average1, hasilrataspo,hasilratarr;

//Inisialisasi tipe data menjadi decimal

Listing Program 3. Program input sensor Max 30100

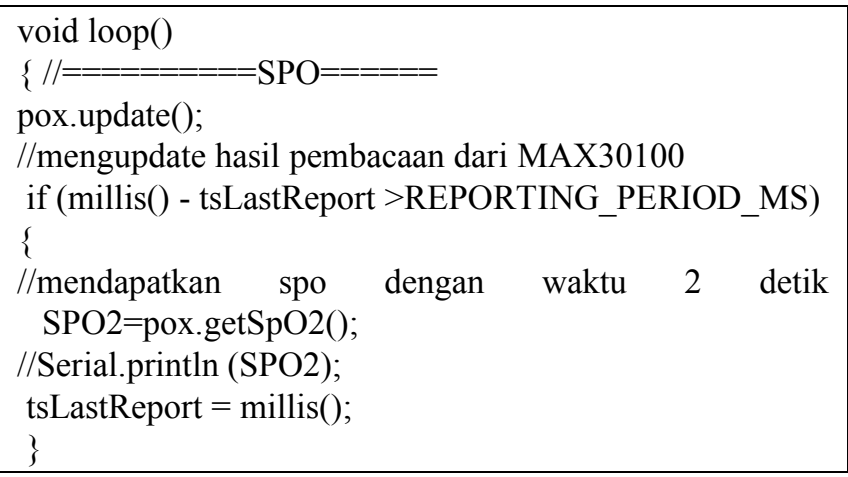

3) Hasil Pengukuran pada Responden

Tabel I dan Tabel II dibawah ini merupakan tabel hasil pengukuran kedua modul (modul sensor Max 30100 dan modul sensor Fingertip Neonatal).

TABEL I. HASIL SENSOR MAX 30100

\begin{tabular}{cccc}
\hline Responden & Nilai Modul & $\begin{array}{c}\text { Nilai } \\
\text { Pembanding }\end{array}$ & Selisih \\
\hline 1 & $100 \%$ & $99 \%$ & $1 \%$ \\
2 & $98 \%$ & $99 \%$ & $1 \%$ \\
3 & $98 \%$ & $99 \%$ & $1 \%$ \\
4 & $98 \%$ & $98 \%$ & 0 \\
5 & $100 \%$ & $99 \%$ & $1 \%$ \\
\hline
\end{tabular}

TABEL II. HASIL PENGUKURAN SENSOR FINGERTIP NEONATAL

\begin{tabular}{cccc}
\hline Responden & $\begin{array}{c}\text { Nilai } \\
\text { Modul }\end{array}$ & $\begin{array}{c}\text { Nilai } \\
\text { Pembanding }\end{array}$ & Selisih \\
\hline 1 & $98 \%$ & $97 \%$ & $1 \%$ \\
2 & $98 \%$ & $99 \%$ & $1 \%$ \\
\hline
\end{tabular}


TEKNOKES, Vol. 13, No. 1, April 2020, pp: 52-59

DOI: $10,35882 /$ teknokes.v13i1.7

\begin{tabular}{llll}
\hline 3 & $100 \%$ & $99 \%$ & $1 \%$ \\
4 & $99 \%$ & $98 \%$ & $1 \%$ \\
5 & $98 \%$ & $97 \%$ & $1 \%$ \\
\hline
\end{tabular}

\section{4) Hasil Pengukuran Jarak Pengiriman HC-05}

Tabel III di bawah ini merupakan tabel hasil pengujian sistem wireless pada kedua modul (modul sensor Max 30100 dan modul sensor Fingertip Neonatal )

TABEL III. HASIL PENGUKURAN JARAK PENGIRIMAN HC-05.

\begin{tabular}{|c|c|}
\hline Jarak Pengukuran & Hasil Pengiriman \\
\hline 1 meter & Terkirim \\
\hline 2 meter & Terkirim \\
\hline 3 meter & Terkirim \\
\hline 4 meter & Tidak terkirim \\
\hline
\end{tabular}

\section{DISKUSI}

Pada penelitian yang dilakukan oleh Adha Nur Qhohar [22] yang melakukan penelitian menggunakan sensor max 30100 pada tabel hasil masih terdapat nilai error $2 \%$ sedangkan pada Tabel I merupakan hasil pencatatan pengambilan data yang dilakukan menggunakan modul sensor Max 30100 yang diletakkan pada ujung jari telunjuk tangan sebelah kanan dan dibandingkan secara langsung dengan menggunakan pulse oximetry yang diletakkan pada ujung telunjuk jari sebelah kiri masing- masing responden. Pada tabel dapat dilihat terdapat perbedaan hasil sebesar 1\% dengan pembanding. Sehingga Pada penelitian ini, nilai error pada hasil lebih kecil.

Pada penelitian yang dilakukan oleh Desak putri Puspita [21] yang membuat penelitian pembuatan Monitoring Spo2 dengan menggunakan metode reflektan (metode yang sama dengan sensor fingertip neonatal). Pada penelitian tersebut masih terdapat hasil SpO2 yang kurang dari 95\% sehingga pada penelitian tersebut hasil masih belum akurat.

Sedangkan pada Tabel II merupakan data hasil pencatatan pada modul dengan sensor fingertip neonatal yang diletakkan pada ujung jari telunjuk kanan responden dan dibandingkan langsung dengan pulse oximetry yang diletakkan pada ujung jari telunjuk sebelah kiri pada masing- masing responden di dapatkan selisih sebesar $1 \%$ terhadap pembanding dari tabel dapat dilihat hasil $\mathrm{SpO} 2$ pada penelitian ini cukup akurat.

Pada penelitian yang dilakukan oleh Desak putri [21] dan pada penelitian yang dilakukan oleh Adha Nur Qahar [22] nilai SpO2 tidak ditampilkan secara wireless. Pada Tabel III merupakan hasil pengujian jarak modul dengan PC yang menampilkan hasil pada pasien, pengujian jarak dilakukan dengan mengubah jarak PC terhadap modul dengan posisi sensor sedang digunakan oleh pasien, di dapatkan hasil bahwa pada jarak 4 meter modul tidak mampu mengirim data pada PC.

\section{KESIMPULAN}

Tujuan dari penelitian ini adalah untuk membuat sebuah alat yang dapat membantu tenaga medis dalam melakukan pemantauan SpO2 bayi prematur secara kontinyu. Penelitian ini telah menemukan bahwa perancangan modul ini dapat digunakan untuk meningkatkan efektifitas pelayanan rumah sakit. Berdasarkan dari hasil pengujian dan pengukuran pada 5 pasien berbeda dengan pembanding pulse oxymeter pada sensor Max 30100 didapatkan nilai selisih sebesar 1\% pada masing-masing hasil pasien, pada sensor fingertip neonatal juga didapatkan nilai selisih $1 \%$.Secara singkat, penelitian ini menemukan bahwa sensor fingertip neonatal dan sensor max 30100 cukup akurat dalam melakukan pembacaan nilai SpO2, dan wireless dengan sistem bluetooth HC-05 merupakan pilihan yang tepat untuk digunakan pada suatu rumah sakit karena dapat mengirimkan data secara real time tanpa adanya gangguan koneksi selama jarak tidak melebihi 3 meter. Penelitian dan eksperimen lebih lanjut diperlukan untuk memperkirakan apakah dapat dibuat sebuah alat pemantauan vital pada pasien yang lebih banyak secara bersamaan.

\section{DAFTAR PUSTAKA}

[1] A. G. Shabeeb, A. J. Al-Askery, and Z. M. Nahi, "Remote monitoring of a premature infants incubator," Indones. J. Electr. Eng. Comput. Sci., vol. 17, no. 3, pp. 1232-1238, 2019.

[2] D. Putri, P. Indriani, and E. L. Utari, "Perancangan Pulse Oximetry Dengan Sistem Alarm Prioritas Sebagai Vital Monitoring," Vol. IX Nomor 27 Nop. 2014 - J. Teknol. Inf., pp. 93-107, 2014.

[3] F. A. Mahapula, K. Kumpuni, J. P. Mlay, and T. F. Mrema, "Risk factors associated with pre-term birth in dar es salaam, tanzania: A case-control study," Tanzan. J. Health Res., vol. 18, no. 1, pp. 1-8, 2016.

[4] M. F. Silveira, C. G. Victora, B. L. Horta, B. G. C. Da Silva, A. Matijasevich, and F. C. Barros, "Low birthweight and preterm birth: Trends and inequalities in four population-based birth cohorts in Pelotas, Brazil, 1982-2015," Int. J. Epidemiol., vol. 48, no. June 2018, pp. I46-I53, 2019.

[5] S. Sowmiya, V. Smrithi, and I. Lorettag, "Monitoring of Incubator using IoT, " vol. 8266, no. 03, pp. 635-638, 2018.

[6] L. Doukkali, F. Z. laamiri, N. B. Mechita, L. Lahlou, M. Habibi, and A. Barkat, "The Issue of Care Given to Premature Infants in the Provincial Hospital Center of Missour," J. Biosci. Med., vol. 04, no. 05, pp. 76-88, 2016.

[7] M. V. Narayana, K. Dusarlapudi, K. Uday Kiran, and B. Sakthi Kumar, "IoT based real time neonate 
monitoring system using arduino," J. Adv. Res. Dyn. Control Syst., vol. 9, no. Special issue 14, pp. 17641772, 2017.

[8] F. R. Ratu and Lia Yuliana, "Faktor-Faktor yang Memengaruhi Kematian Bayi Prematur di Indonesia," vol. 1, no. November, 2017.

[9] M. Subramanian, T. Sheela, K. Srividya, and D. Arulselvam, "Security and health monitoring system of the baby in incubator," Int. J. Eng. Adv. Technol., vol. 8, no. 6, pp. 3582-3585, 2019.

[10] W. Chen, S. B. Oetomo, L. Feijs, S. Bouwstra, I. Ayoola, and S. Dols, "Design of an integrated sensor platform for vital sign monitoring of newborn infants at Neonatal Intensive Care Units," J. Healthc. Eng., vol. 1, no. 4, pp. 535-554, 2010.

[11] K. B. Long C., Saedler K., “乳鼠心肌提取 HHS Public Access," Physiol. Behav., vol. 176, no. 1, pp. 139-148, 2016.

[12] M. . Kemalasari, Ir., "Rancangan Bangunan Pulse Oximetry Digital," 2010.

[13] H. F. Dian Bagas Setyo Budi, Rizal Maulana, "Sistem Deteksi Gejala Hipoksia Berdasarkan Saturasi Oksigen Dengan Detak Jantung Menggunakan Metode Fuzzy Berbasis Arduino," J. Pengemb. Teknol. Inf. dan Ilmu Komputer., vol. 3, no. 2, pp. 1925-1933, 2019.

[14] A. Kaunang, R. Wilar, and J. Rompis, "Perbandingan Kadar Saturasi Oksigen Hari Pertama," J. e-Clinic, vol. 3, no. April, pp. 397-401, 2015.

[15] L. Valizadeh, M. Mahallei, A. Safaiyan, F. Ghorbani, and M. Peyghami, "The effect of plastic cover on regulation of vital signs in preterm infants: A randomized cross-over clinical trial," Iran. J. Neonatol., vol. 8, no. 2, pp. 24-30, 2017.

[16] O. Access, “A Wireless Based Temperature, Humidity and Light Intensity Monitoring System for Child Incubators," vol. 2, no. 3, pp. 67-71, 2015.

[17] R. Dilip, "DESIGN AND DEVELOPMENT OF INTELLIGENT SYSTEM FOR HUMAN BODY DESIGN AND DEVELOPMENT OF INTELLIGENT SYSTEM FOR HUMAN BODY," no. July, pp. 0-3, 2019.

[18] M. Shelar, J. Singh, and M. Tiwari, "Wireless Patient Health Monitoring System," Int. J. Comput. Appl., vol. 62, no. 6, pp. 1-5, 2013.

[19] Sujithanand A, Srinivasan S, Abishek K, and Nagaraju $\mathrm{N}$, "Infant Incubator Monitoring system with Remote Access (IIMRA)," Int. J. Innov. Res. Sci. Eng.

[20] A. Rajalakshmi, K. A. Sunitha, and R. Venkataraman, "A survey on neonatal incubator monitoring system," J. Phys. Conf. Ser., vol. 1362, no. 1, 2019.
[21] D. Putri, P. Indriani, and E. L. Utari, "Perancangan Pulse Oximetry Dengan Sistem Alarm Prioritas Sebagai Vital Monitoring," Vol . IX Nomor 27 Nop. 2014 - J. Teknol. Inf., pp. 93-107, 2014.

[22] A. N. Qahar, "Desain Alat Ukur Denyut Jantung Dan Saturasi Oksigen Pada Anak Menggunakan Satu Sensor," pp. 4-7, 2018. 